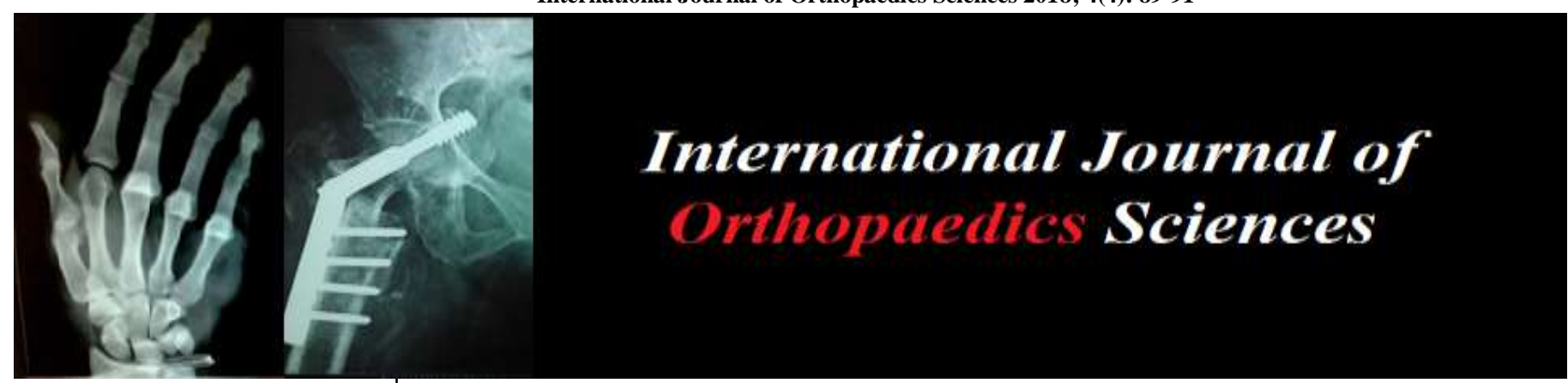

ISSN: $2395-1958$

IJOS 2018; 4(4): 89-91

(C) 2018 IJOS

www.orthopaper.com

Received: 21-08-2018

Accepted: 24-09-2018

\section{Aavrati Rastogi}

BPT, MPT (Musculoskeletal)

Physiotherapist Department of

Physical Medicine and

Rehabilitation, King George

Medical University, Lucknow,

Uttar Pradesh, India

\section{Correspondence}

Aavrati Rastogi

BPT, MPT (Musculoskeletal)

Physiotherapist Department of

Physical Medicine and

Rehabilitation, King George

Medical University, Lucknow,

Uttar Pradesh, India

\section{Rehabilitation of femoral afibular amelia: A case report}

\section{Aavrati Rastogi}

DOI: https://doi.org/10.22271/ortho.2018.v4.i4b.19

\section{Abstract}

Congenital limb defects are fetal anomalies with birth. Amelia is extremely rare birth defect marked by the complete absence of or more limbs. Congenital limb defects are rare fetal anomalies with a birth prevalence of 0.55 per 1,000. Amelia is an extremely rare birth defect marked by the complete absence of one or more limbs. We report a case of fetal amelia, ultrasound findings, manifestations and the fetal outcome. We report a case of a femoral fibular amelia x-ray findings and the other outcomes.

Keywords: Amelia; congenital; limb defects sporadic rare

\section{Introduction}

Amelia, defined as the complete absence of the skeletal parts of a limb, is generally thought to be a sporadic anomaly ${ }^{[1]}$. It can present as an isolated defect or with associated malformations, particularly abdominal wall and renal anomalies ${ }^{[2-4]}$. Teratogens such as thalidomide, alcohol, vascular compromise by amniotic bands or other causes, and maternal diabetes have been reported to cause this severe limb deficiency ${ }^{[5-8]}$. Amelia is a rare condition with an incidence range from 0.053 to 0.095 in 10,000 live births ${ }^{[9,10]}$.

Congenital defects of the femur vary from simple hypoplasia of the bone to complete absence. Classification of these defects has been suggested by Nilsonne (1928) and by Mouchet and Ibos (1928), but neither has met with general acceptance. In more recent years Golding (1939, 1948) has demonstrated the close association of the short femur with congenital coxa vara, and has emphasized that these are variations of the same underlying abnormality. The clinical distinction between the various types of femoral defect is important as a guide to the prognosis of limb development. From an examination of patients with congenital abnormalities of the femur the following classification is suggested:

1. Simple femoral hypoplasia.

2. Congenital coxa vara.

3. Femoral hypoplasia with coxa vara.

4. Pseudarthrosis of the femur.

5. Hypoplasia of the lower femoral epiphysis.

6. Complete absence of the femur.

Although these patients commonly have other skeletal defects, the major congenital abnormalities affecting the nervous system, or in the chest and abdomen, appear to be rare. Their span of life is thus rarely affected, and detailed autopsy or pathological examination of the limb is rarely possible. From the clinical examination of these patients, however, and from serial radiographs, much information can be obtained about the clinical course of the limb abnormality, and the nature of the underlying disturbance of growth. The extreme rarity of this congenital anomaly has stimulated this report on a new case present at DPMR, KGMU, LKO.

\section{Case Report}

A 14 year old female child was admitted in DPMR, KGMU, LKO with complain of congenital left lower limb shortening. She was noted no change in ADL's but have difficulty in walking. Since birth one lower limb was unusually short. The patient was uneventful, with normal development, according to her mother she was fully immunised. She was noted no change in 
urinary or bowel habits.

She had no fever or night sweat and no cardiac, respiratory or gastrointestinal symptoms. Physically examination of lower limb with equinus deformity in left foot.

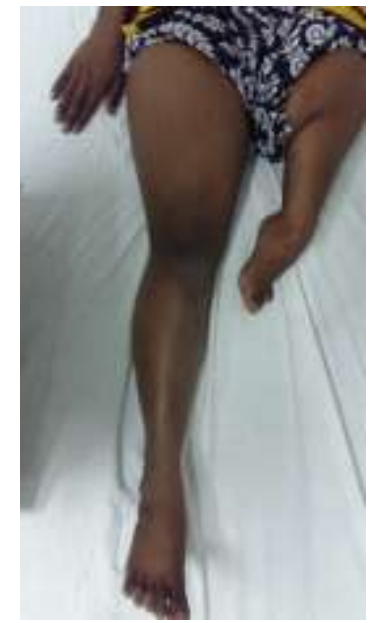

Unusually short left lower limb

\section{Investigations}

\section{Radiological Examination}

Left lower limb consist of tilted pelvis towards left side. Left knee joint was situated inside the acetabulum including the reminent part of femur is also seen in the acetabulum, with shortening \& equinus deformity in left foot.

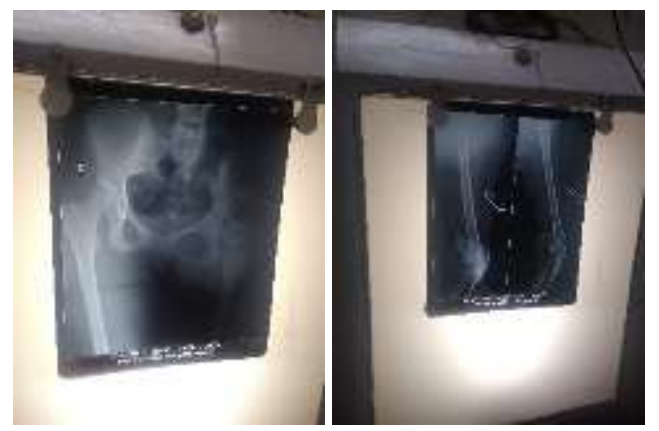

\section{Neurological Examination}

On physical examination, patient was well oriented, cooperative, cranial nerves and higher centres were intact.

\section{Sensory Examination}

On sensory examination it was found the senses were within the limit.

\section{Motor Examination}

On the motor examination it was found: Tone-was normal, Co-ordination-was positive, Abnormal movement - There was no abnormal movement in both upper and right lower limb, Muscle power - muscle power of both upper limb and right lower limb was full i.e, 5/5 which was in the limit but muscle power of left lower limb cannot be tested due to equinus deformity.

\section{Reflexes}

\section{Upper limb}

Reflexes of upper limb biceps, triceps \& supinator are positive in both upper limbs.

\section{Lower limb}

In right lower limb and ankle, reflexes are positive including planter flexors. In left lower limb knee and can be tested but in foot there is equinus deformity present.

\section{Gait analysis}

It was also done to confirm the patient's gait.

\section{Treatment}

\section{Surgical procedure}

Surgical procedure was planned for left ankle in which achilles tendon lengthening was done.

\section{Physiotherapy management}

After achilles tendon lengthening patient was managed conservatively with left extension ischial weight bearing prosthesis and gait training. Patient was two months under gait training and after proper gait training patients was able to walk normally with the help of prosthesis. Patient can perform her ADL's as earlier.

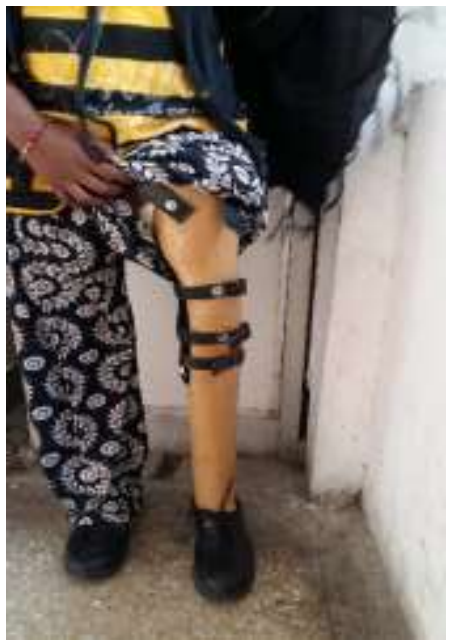

Left Lower limb extension ischial weight bearing prosthesis

\section{Discussion}

Amelia was traditionally thought to be a sporadic anomaly with little risk of recurrence, or evidence of genetic origins. However, different modes of inheritance has been involved in the etiology of Amelia including autosomal recessive, $\mathrm{X}$ linked dominant and autosomal mode of inheritance which indicate the genetic heterogeneity of this condition ${ }^{[11]}$.

We report a female patient with congenital left femoral fibular amelia with eqinus deformity. Both upper and right lower limb were normal the patient can perform her ADL's. All the vital organs were working properly. Left lower limb consist the pelvis tilted towards left side. Left knee joint was situated inside the acetabulum including the reminent part of femur is also seen in acetabulum with $40 \mathrm{~cm}$ shortening. There was no family history of limb anamalies. To our knowledge this was the first case reported in her family.

As organ malformations have been reported to be frequently associated with cases of Amelia ${ }^{[12]}$, the possibility of the recurrence of amelia has been documented in only a few families ${ }^{[13-15]}$. In this case, pregnancy and family history were non-contributory factors regarding genetic orteratogenic causes; maternal infection also appears to be unlikely. It is difficult to progress further in the etiology of this case. These parents were counselled for a low recurrence rate and advised to have an early anomaly scan in future pregnancies.

\section{References}

1. Lenz W. Genetics and limb deficiencies. Clin Orthop 
Relat Res. 1980; (148):9-17.

2. Froster-Iskenius UG, Baird PA. Amelia: incidence and associated defects in alarge population. Teratology. 1990; 41(1):23-31.

3. Evans JA, Vitez M, Czeizel A. Patterns of acrorenal malformation associations. Am J Med Genet. 1992; 44(4):413-419.

4. Mastroiacovo P, Kallen B, Knudsen LB, Lancaster PA, Castilla EE, Mutchinick O, et al. Absence of limbs and gross body wall defects: an epidemiological study of related rare malformation conditions. Teratology. 1992; 46(5):455-464.

5. Smithells RW, Newman CG. Recognition of thalidomide defects. J Med Genet. 1992; 29(10):716-723.

6. Pauli RM, Feldman PF. Major limb malformations following intrauterine exposure to ethanol: two additional cases and literature review. Teratology. 1986; 33(3):273280.

7. Van Allen MI, Curry C, Walden CE, Gallagher L, Patten RM. Limb body wall complex: II. Limb and spine defects. Am J Med Genet. 1987; 28(3):549-565.

8. Bruyere HJ Jr, Viseskul C, Opitz JM, Langer LO Jr, Ishikawa S, Gilbert EF. A fetus with upper limb amelia, caudal regression and Dandy-Walker defect with an Insulin-Dependent diabetic Mother. Eur J Pediatr. 1980; 134(2):139-143.

9. Bod M, Czeizel A, Lenz W. Incidence at birth of different types of limb reduction abnormalities in Hungary 1975-1977. Hum Genet. 1983; 65(1):27-33.

10. Kallen B, Rahmani TM, Winberg J. Infants with congenital limb reduction registered in the Swedish Register of Congenital Malformations. Teratology. 1984; 29(1):73-85.

11. Morey MA, Higgins RR. Ectro-amelia syndrome associated with an interstitial deletion of 7q. Am J Med Genet. 1990; 35(1):95-99.

12. Song SY, Chi JG. Tri-amelia and phocomelia with multiple malformations resembling Roberts's syndrome in a fetus: is it a variant or a new syndrome? Clin Genet. 1996; 50(6):502-504.

13. Zimmer EZ, Taub E, Sova Y, Divon MY, Pery M, Peretz BA. Tetra-Amelia with multiple malformations in six male fetuses of one kindred. Eur J Pediatr. 1985; 144(4):412-414.

14. Gershoni-Baruch R, Drugan A, Bronshtein M, Zimmer EZ. Roberts syndrome or X-linked amelia? Am J Med Genet. 1990; 37(4):569-572.

15. Rodriguez JI, Palacios J, Urioste M, Rodriguez-Peralto JL. Tetra-phocomelia with multiple malformations: Xlinked amelia, or Roberts syndrome, or DK phocomelia syndrome? Am J Med Genet. 1992; 43(3):630-632. 